\title{
The role of values and of socioeconomic status in the education-fertility link among men and women
}

\author{
Martin Lakomý*
}

\begin{abstract}
This paper utilizes an untapped data source containing information about completed fertility rates and many explanatory variables to elaborate the education-fertility link. Indicators of the theory of value change and rational choice theory are tested as possible explanations for this relationship. A Poisson regression is used to analyze data from the fourth wave of the European Values Study, with the number of children as the dependent variable. The association between education and fertility is found to be generally negative and stronger for women. The findings also indicate that opportunity costs and liberal values are stronger predictors of fertility among women than among men, and largely explain the more negative effect of education on women. Additional analysis of different welfare regimes reveals that the multivariate association between education and fertility remains significant only for the post-communist countries of Europe.
\end{abstract}

\section{Introduction}

One of the most important individual characteristics associated with fertility behavior is the level of education (Lutz 2010). Education is strongly tied to fertility behavior in both developed (James et al. 2012; Neels and De Wachter 2010; Sobotka 2004) and developing countries (Bongaarts 2010; Cleland 2002; Dreze and Murthi 2001). The shift to higher education is considered the main cause of the fertility postponement trend, the overall reduction in fertility, the higher rates of childlessness, and the greater emphasis placed on liberal values and areas of life not related to family formation (James et al. 2012; Neels and De Wachter 2010). The fertility behavior of the most educated members of society is becoming increasingly important as the number of college-educated people grows, and their impact on

\footnotetext{
* Martin Lakomý, Department of Sociology/Office for Population Studies, Masaryk University, Brno, Czech Republic

Email: martinlakomy@seznam.cz
} 
societal norms and values increases (Van Bavel and Rózańska-Putek 2010). James et al. $(2012,7)$ have asserted that the "education-fertility link is something which is universal in nature, irrespective of culture, context, geography, or the level of fertility transition." Is the education-fertility link really universal? James et al. (2012) argued that this link is probably not weakening in the context of low fertility: i.e. that a lower fertility rate is likely to lead to decreased variation in fertility, but not to a weaker effect of education itself.

However, the association between education and fertility has varied among countries and cohorts, as well as by sex. The education-fertility link has been diminishing in the Nordic countries in particular, probably due to their egalitarian social and gender policies (Andersson et al. 2009; Kravdal and Rindfuss 2008). Moreover, Eurostat data indicate that the contemporary total fertility rate is higher among more educated women in certain European countries, mainly in Denmark, Finland, and Norway (Lanzieri 2013). Other studies that have examined recent changes in the education-fertility link have found a positive effect of women's education on third-birth intensities in Austria (Hoem 2003), and on both secondbirth and third-birth intensities in Norway (Kravdal 2007). Still, to the best of my knowledge, no study has conclusively presented a reversal of the effect of women's education on completed fertility.

The majority of the existing fertility research has been concerned with female fertility. Until recently, there were very few studies that had investigated male fertility. The more recent studies have shown that the education-fertility link is slightly positive for men, especially in the Nordic countries (Kravdal and Rindfuss 2008; Lappegård and Rønsen 2013; Nisén et al. 2014); and that it ranges from positive to negative in other western countries (Barthold et al. 2012; Toulemon et al. 2008; Zhang 2011). Two studies that followed the changes in men's fertility over time found a more positive effect of education among younger cohorts in Norway (Kravdal and Rindfuss 2008), and a less negative effect of education among younger cohorts in France (Toulemon et al. 2008).

The education-fertility link depends on the macro context, which may be conceptualized through, for instance, Esping-Andersen's (1990) division of developed countries into three types of welfare states: Social Democratic, Liberal, and Conservative. This research, which focused on both women and men, clearly asserted that the country, welfare regime, and cohort contexts all help to shape the education-fertility link; and that cross-national analysis should take these contexts into account.

I argue that the effect of education is not a universal effect or an effect of educational attainment, but is instead a combination of the effects of other characteristics connected to education. The aim of this paper is to examine the nature of the education-fertility link and to explore some of the ways in which education affects fertility behavior. Data from the European Values Study project are used to obtain a) representative samples from all over Europe, b) information about completed fertility levels, and c) measurements of some important explanatory variables that are usually not asked in surveys. Values connected to the second 
demographic transition (SDT) and socioeconomic status (as measured by the individual's position in the labor market) are tested as possible mediators of the education-fertility link.

\section{Theoretical background}

Some recently published studies have raised doubts about the universality of the education-fertility link (Andersson et al. 2009; Hoem 2003; Lanzieri 2013). It appears, however, that this association is still a strong and highly prevalent phenomenon (Aldieri and Vinci 2013; Sobotka 2004; Zhang 2011). As it is clear that education affects fertility in many different ways, the most important question to ask is how this link works.

One of the ways in which education affects fertility is through educational enrollment, or the length of the educational process (Dribe and Stanfors 2009; Sobotka 2004); as individuals who are enrolled in education tend to postpone parenthood and have less time for childbearing. While I do not address the effect of educational enrollment in this paper, I mention it here as a reminder of the complexity of the issue. Involvement in the educational process does not simply lead to a postponement childbearing; it simultaneously changes many aspects of human life, and is also a result of many aspects of human life. Education thus has many indirect effects on fertility. Highly educated individuals may be indirectly influenced in their fertility decisions by, for example, high opportunity costs associated with childbearing, increased resistance to normative pressure, liberal values (autonomy, independence, and self-realization), having effective control over their fertility, and having a strong focus on their career (Sobotka 2004).

In this paper, I employ two broad theoretical frameworks that are widely used for explaining educational differences in fertility. Rational choice theory assumes that childbearing is a fully controlled and rationally driven behavior, and that "in deciding to have a child, people make the considered calculation that the benefits of an additional child outweigh the costs" (McDonald 2002, 422). Theories based on value changes assume that developed societies have created an environment in which there has been a shift toward more liberal values that has resulted in decreased fertility, and that this shift in values has been primarily driven by people with higher education (Lesthaeghe 2010).

How do rational choice approaches explain the association between fertility and education? Parents with higher levels of education tend to put greater emphasis on the quality than on the quantity of children (Becker and Lewis 1974); this implies that parents invest more in a smaller number of offspring. Particularly for women, having higher levels of education and of potential wages means that the opportunity costs of childbearing are also high (Brand and Davis 2011; Kravdal and Rindfuss 2008). On the other hand, among men in particular, the higher level of income that tends to come with having a higher level of education could outweigh the higher opportunity costs of childbearing, and enable them to have more children (Kravdal 
and Rindfuss 2008; Neels and De Wachter 2010). Fertility behavior is influenced by the economic circumstances of individual women and families, as well as by macroeconomic conditions. Economic instability or recessions may depress the fertility of women with higher levels of education and increase the fertility of some groups of women with lower levels of education (Sobotka et al. 2011).

A basic assumption underlying these explanations is that people control and plan their fertility behavior, but this assumption has become valid only recently, through increased access to effective contraceptive methods (Inglehart 1990). Moreover, access to effective contraceptives and knowledge about contraceptive use remain unequally distributed, even in developed countries that have undergone the SDT. Compared to their better educated counterparts, women with lower levels of education have been shown to use modern contraception less often or less effectively in the United States (Musick et al. 2009), in Belgium (Neels and De Wachter 2010), and elsewhere around the world (James et al. 2012). Musick and her colleagues (2009) offered support for this idea by noting that the numbers of intended births in the United States are very similar among educational groups, while the numbers of unintended births are much higher among less educated mothers than among more educated mothers. They therefore concluded that the educational gradient in fertility can be primarily attributed to this gap in unintended births.

Theories based on value changes form the second most widely used group of theories explaining fertility behavior and the education-fertility link. Several interrelated theories and concepts, such as the SDT framework (Lesthaeghe 2010), and the theories that a shift toward a post-materialist (Inglehart 1971, 1990) or a post-modern value orientation is occurring (van de Kaa 2001), share one basic idea. In stable, developed societies, people now take it for granted that their basic material needs will be met, and are increasingly interested in satisfying higher-level needs, such as the desire for a higher quality of life, a cleaner environment, greater personal freedom, and opportunities for self-realization and self-expression (Inglehart 1990; Lesthaeghe 2010; van de Kaa 2001). As Lesthaeghe (2010, 213) put it, "With such a shift in needs, a shift in the values structure would also occur, with tolerance for diversity and respect for individual choices gradually taking over as prime values from solidarity and social group adherence and cohesion."

This new value system - which has been variously called post-materialist, post-modern, post-transitory, or liberal by different theoretical approaches - is associated with lower fertility; despite indications that the fertility preferences of post-materialists or post-modernists are higher than their actual fertility (Bachrach 2001; van de Kaa 2001). A possible explanation for why people who hold more liberal values are often unable to fulfill their fertility preferences is that such people tend to be involved in many areas of life that are in conflict with family life, and generally have high expectations about their quality of life and the quality of their partnerships (Bachrach 2001; Mareš 2008; van de Kaa 2001). While sex differences in the effects of liberal values have not yet been examined, it appears that women experience greater conflicts in more areas of life than men (because motherhood is a more time- and opportunity-consuming role). 
Liberal values are strongly linked to education (Inglehart 2008; van de Kaa 2001); accordingly, because their liberal value system is not primarily focused on family and childbearing, we can expect to find that highly educated people have relatively low fertility levels (Inglehart 1990). It is also likely that more educated individuals (especially women) with high fertility intentions will nonetheless have actual fertility levels similar to those of more liberal women. The main obstacles to childbearing for more educated women are high opportunity costs, while the main obstacles to childbearing for more liberal women are related to their tendencies to engage in a wide range of activities and to place a greater emphasis on quality of life (Testa 2014; van de Kaa 2001). Another potential reason why people who are more liberal and more educated have lower fertility levels is that they are more resistant to normative pressure (Kravdal and Rindfuss 2008).

Research on values has traditionally focused on the stability of value orientation, which is largely formed during the process of socialization in the pre-adult years (Inglehart 1971, 1990), and which generally remains relatively stable over time (Inglehart 1981, 1985; Rokeach 1979; Schwarz 2005). However, the evidence for the relative stability of values has been called into question, with some studies arguing that values can change following important life events, such as getting married or having children. More precisely, people may choose their life transitions in accordance with their values, but the importance people place on those values may change in response to shifts in life circumstances (Bardi and Goodwin 2011; Bardi et al. 2009, 2014; Lesthaeghe and Moors 2002; Rokeach 1985). Hence, childbearing can be guided by a person's value orientation, and can, at the same time, modify it.

There are some indications that the tendency to have a liberal or a traditional value orientation is stable over time. Thus, it appears that people have values that are "deep-lying components of collective belief systems" (Rokeach and BallRokeach 1989, 777), and moral values (Goren 2005) that are part of a consistent value hierarchy (Mikołajczak and Pietrzak 2014). Still, it is not possible to estimate the extent to which the value orientation of an individual remains at least roughly the same or changes during her life course. The claim that there is an association between values and fertility therefore needs to be interpreted very carefully in terms of causality.

Rational choice theory asserts that the effect of education on fertility is mediated by the different costs and benefits of parenthood experienced by different educational groups (Brand and Davis 2011; Neels and De Wachter 2010). According to the theory of value change, the same effect is mediated by different value systems (Inglehart 1990, 2008; van de Kaa 2001). Therefore, the arguments of both theories lead us to assume that the education-fertility link is not fixed and universal, as it can be explained by other individual characteristics that vary both within and among educational groups. Like economic, technological, and cultural factors, social policy should affect the fertility behavior of different educational groups in different ways. Generally speaking, direct financial support and financial benefits for families seem to encourage childbearing among the less wealthy and the less educated groups, whereas policies aimed at reducing work-family conflicts tend to 
boost fertility primarily among the more educated groups (Thévenon and Gauthier 2011). Nevertheless, the effects of social policies are not entirely clear. In a complex social reality, it is always difficult to determine whether a social policy has led to changes in fertility levels, or simply in the timing of births (Gauthier 2007).

In sum, there are many ways in which education and issues related to education affect fertility behavior. In this paper, I seek to make this relationship more comprehensible by controlling for two possible mediators: socioeconomic status and the values associated with the SDT. I hypothesize that the association between education and fertility is generally negative, and is stronger among women than among men. In addition, I expect to find that this link can be explained primarily by the more liberal values of people with higher levels of education. I also hypothesize that socioeconomic status, an indicator of rational choice theory, has strong explanatory power in this association. I further argue that the effect of education is context-dependent, and that the observed link is largely explained by the characteristics connected with education (such as the values associated with the SDT and with socioeconomic status) - but also that these characteristics can be partly caused by education itself. Thus, I expect to find that the education-fertility link is diminished after controlling for selected key factors in the analysis.

\section{Data and measures}

\subsection{Data and sample}

To investigate the education-fertility link, I draw upon data from the European Values Study (EVS) project. This large-scale data collection works with national representative samples. Respondents are asked about their values, attitudes, and opinions. There have been four waves of data collection from 1981 onward. Each wave has used almost the same standardized questionnaire. As a new sample of respondents is created for each wave, the EVS is not a panel study.

My analysis uses data from the fourth wave of the EVS collected in 2008, which covered 47 countries. ${ }^{1}$ Because I wanted to focus on the European region only, I excluded the non-European countries (Armenia, Azerbaijan, Cyprus, Georgia, and Turkey) and the countries and regions with a politically unclear or unstable status at the time of the data collection (Kosovo, Montenegro, Northern Ireland, and Northern Cyprus). My dataset thus includes 38 European countries representing all of the

\footnotetext{
1 This wave contains 67,774 valid interviews with 30,161 men and 37,613 women between 18 and
} 108 years of age, and the response rate was 52.4 percent (European Values Study 2010). 
broader geographical regions of Europe. ${ }^{2}$ I restricted the original sample to men over age 50 and to women over age 40 in order to create a sample with (mostly) completed fertility; ${ }^{3}$ respondents over age 80 were dropped due to the different context of their life course. I then kept only the respondents with some working experience, since I needed information about their current or former socioeconomic status. ${ }^{4}$

\subsection{Measurement of variables}

As my main goal is to examine fertility, the number of children is the dependent variable of the study. This information was measured by the direct question, "How many children do you have?" The dependent variable "number of children" has the properties of unimodal and positively skewed count data with relatively small values, and thus has the potential to fit the Poisson distribution ${ }^{5}$ (Marchini 2008). Hence, I decided to use a Poisson regression to obtain the multivariate associations in the final part of the analysis.

Education is the main explanatory variable in this paper. Education was measured in the EVS according to the International Standard Classification of Education (ISCED). I divided the ISCED scale into three categories: 0-2 (primary education or lower), 3-4 (secondary education), and 5-6 (tertiary education).

Other explanatory variables expected to mediate the effect of education are the items on the current or last occupation $(0-100)$ from the International SocioEconomic Index of Occupational Status (ISEI), and all of the items related to values

\footnotetext{
2 The countries in the dataset, organized by welfare regime category, are as follows: Denmark, Finland, Iceland, Norway, and Sweden representing the Social Democratic welfare model; Ireland, Switzerland, and the United Kingdom representing the Liberal welfare model; Austria, Belgium, France, Germany, Greece, Italy, Luxembourg, Malta, the Netherlands, Portugal, and Spain representing the Conservative welfare model; Albania, Bosnia and Herzegovina, Bulgaria, Croatia, the Czech Republic, Hungary, Macedonia, Poland, Romania, Serbia, Slovakia, and Slovenia representing the Post-Communist model; and Belarus, Estonia, Latvia, Lithuania, Moldova, Russia, and Ukraine representing the Post-Soviet model. Countries are sorted according to the classical typology of Esping-Andersen (1990), with two additional groups of post-communist countries added by Ebbinghaus (2012) and Fenger (2007).

3 In Europe, approximately two percent of children are born to women over the age of 40 (Human Fertility Database 2015). The same information for men is available for the United States only, where less than one percent of children are born to men over the age of 50 (Center for Disease Control and Prevention 2012).

4 Four percent of men and 11 percent of women were dropped because they had never worked.

5 The data distribution has a mean of 2.09 and a variance of 1.55 for men; the respective values for women are 1.99 and 1.51. These values indicate that there is a small underdispersion of the data, which is confirmed by the dispersion ratios of 0.64 for men and 0.68 for the final model. Nevertheless, the Poisson distribution still provides the best fit to the data, and the mild underdispersion was easy to adjust for in the analysis (Dallal 2008).
} 
and attitudes ${ }^{6}$ from the Index of the Second Demographic Transition (hereafter, the SDT value index) constructed by Sobotka (2008a, 2008b). I use the ISEI as a proxy for opportunity costs, as the rational choice approach measures opportunity costs in terms of income lost due to childbearing (Brand and Davis 2011). The items from the SDT value index, all of which are included in the EVS questionnaire, were used to indicate whether each respondent has a liberal or a traditional value orientation. As various items from the SDT value index were measured using different scales, Sobotka (2008b) dichotomized all of the responses to create a prevalence of SDT values score for each country (i.e. how many respondents in a given country held a particular liberal value), and summed the values in a single index (0-10) measured at the country level (Sobotka 2008b).

In this study, the intended indicator of a liberal or traditional value system is the SDT value index constructed on the respondent level: the sum of the dichotomized items with the traditionally oriented responses were coded with a value of zero, and the liberally oriented responses were coded with a value of one. Validating the SDT value index at the individual level is problematic because of very low degree of internal consistency; Cronbach's alpha is 0.35 in the sample of men and 0.42 in the sample of women. There are also few if any correlations between items. I have therefore chosen to use single components rather than a single scale in the analysis. Using this technique, I was able to create a theoretically grounded set of value indicators (Lesthaeghe 2011; Sobotka 2008b; Surkyn and Lesthaeghe 2004), and to control for the predictive power of particular values in the analysis of fertility behavior. This step should not affect the results of the analysis, because the single value items work in the same way as the summed individual SDT value index. Finally, I control for some other variables, such as age group (40-49, 50-59, 60-69, and 70-79), marital status (currently or previously married, never married), and country.

In this large sample, a control for country would not create any comprehensible patterns. Moreover, social policies seem to be the decisive macro factor in the

6 Items were:

1. ... how important it is in your life: leisure time - very important

2. How often do you attend religious services these days? - less than every week

3. Please use the scale to indicate how much freedom of choice and control you feel you have over the way your life turns out - more control after dichotomization

4. Do you think that a woman has to have children in order to be fulfilled, or is this not necessary? not necessary

5. Marriage is an outdated institution - agree

6. A job is alright, but what most women really want is a home and children - not strongly agree

7. One does not have the duty to respect and love parents who have not earned it by their behavior and attitudes - agree

8. Do you approve or disapprove of abortion (...) when a married couple does not want to have any more children? - approve. 
relationship between education and fertility (Andersson et al. 2009; Bavel and Rozanska-Putek 2010; Kalwij 2010; Kravdal and Rindfuss 2008). I have therefore chosen to divide the countries into five welfare regime categories. While these welfare regimes were originally defined by Esping-Andersen (1990), Ebbinghaus (2012) and Fenger (2007) subsequently added more countries and welfare models. To achieve more context-sensitive results, I have categorized the countries according to their welfare models for some parts of the analysis. The welfare regime classifications (Social Democratic, Liberal, Conservative, Post-Communist, and Post-Soviet) of all of the countries are listed in footnote 2 above.

I excluded the respondents of reproductive age (women below age 40 and men below age 50, with an upper limit of age 80 for both sexes) and cases with missing values. After these steps, 6,822 men and 12,198 women remained in the final samples. For each country, there are between 62 and 285 respondents in the sample of men and between 156 and 486 respondents in the sample of women. The respondent numbers for all of the countries are sufficient for statistical purposes, as I am more interested in discerning a general pattern than in measuring cross-national differences. The sample for each sex is analyzed separately to test for differences between men and women in the examined relationship.

\section{Results}

\subsection{Descriptive statistics}

The basic properties of the two samples are shown in Table 1 . The sample of women is larger and younger than the sample of men. Because of the difference in the age ranges of the samples, slightly more of the women than of the men had not yet married, and slightly more children had been born to the men than to the women. The other properties of the samples, including values and socioeconomic status, are similar.

\subsection{Education-fertility link}

The first step of the analysis is to determine how the average number of children varies across categories of education. Additionally, I seek to obtain differences in the education-fertility link across the five European welfare regimes. Figure 1 shows that men with lower levels of education have slightly more children than men with higher levels of education. While this pattern can be seen across all of the welfare regimes apart from the Social Democratic regime, these differences are not very large, especially between the categories of secondary and tertiary education. In total, the average numbers of children are 2.22 per man with primary education, 2.02 per man with secondary education, and 2.01 per man with tertiary education. Figure 2 shows that for the sample of women, education has a much more pronounced 
Table 1:

Descriptive statistics of the two analyzed samples

\begin{tabular}{|c|c|c|}
\hline & Men & Women \\
\hline \multicolumn{3}{|l|}{ Number of children (column percentages) } \\
\hline 0 & 9.9 & 9.9 \\
\hline 1 & 16.7 & 20.1 \\
\hline 2 & 44.8 & 44.6 \\
\hline 3 & 18.4 & 17.4 \\
\hline $4+$ & 10.2 & 8.0 \\
\hline \multicolumn{3}{|l|}{ Education (column percentages) } \\
\hline ISCED 0-2 & 34.5 & 33.6 \\
\hline ISCED 3-4 & 42.3 & 43.0 \\
\hline ISCED 5-6 & 23.2 & 23.4 \\
\hline \multicolumn{3}{|l|}{ Age group (column percentages) } \\
\hline $40-49$ & no & 32.6 \\
\hline $50-59$ & 43.0 & 29.4 \\
\hline $60-69$ & 35.1 & 23.5 \\
\hline $70-79$ & 21.9 & 14.5 \\
\hline Leisure time (\% of "very important") & 32.9 & 33.5 \\
\hline Religious services (\% of "not often") & 82.6 & 78.5 \\
\hline Control over life (\% of "more control") & 59.4 & 57.0 \\
\hline Women need children (\% of “no”) & 37.8 & 41.4 \\
\hline Marriage outdated institution (\% of "yes") & 19.0 & 19.8 \\
\hline Women really want home (\% of "no") & 82.0 & 83.0 \\
\hline Duty to respect parents (\% of “no") & 26.4 & 28.9 \\
\hline Abortion (\% of “approved”) & 51.1 & 53.3 \\
\hline ISEI (mean) & 42.9 & 42.1 \\
\hline \multicolumn{3}{|l|}{ Marital status (column percentages) } \\
\hline Married currently or formerly & 94.5 & 92.9 \\
\hline Never married & 5.5 & 7.1 \\
\hline
\end{tabular}

Source: EVS 2008.

negative effect. The respective averages for the three levels of education are 2.27, 1.90, and 1.77; and these differences are similar across the welfare regimes.

A comparison of the two figures provides a clear picture of the gender differences. The association between education and the number of children is relatively small for men and is relatively large for women; which is not surprising considering the higher opportunity costs of parenthood for women. Some distinctions between western and eastern Europe appear in the data; for example, the effect of education seems to be stronger in countries with Post-Communist welfare regimes. 
Figure 1:

The average number of children by education and welfare regime (male sample)

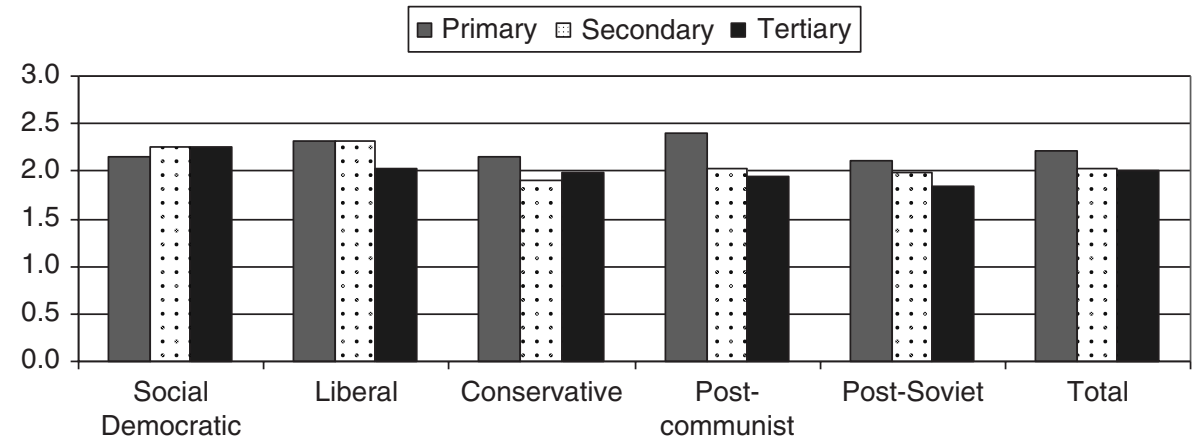

Source: EVS 2008.

Figure 2:

The average number of children by education and welfare regime (female sample)

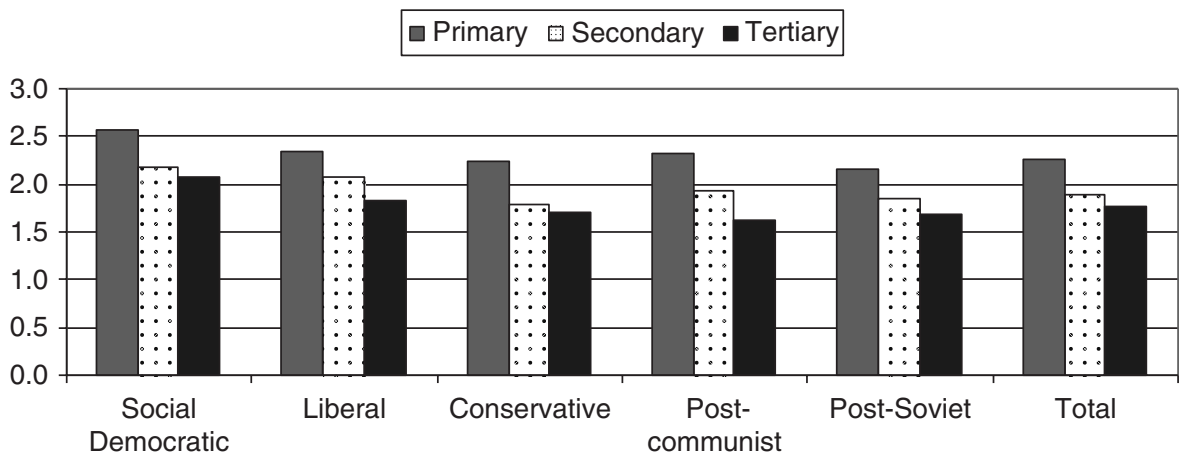

Source: EVS 2008. 
Table 2:

Unstandardized coefficients B of the Poisson regression for the "number of children" variable (male sample)

\begin{tabular}{|c|c|c|c|c|}
\hline & Model 1 & Model 2 & Model 3 & Model 4 \\
\hline Intercept & $0.734^{* * *}$ & $0.970^{* * *}$ & $0.743^{* * *}$ & $3.286^{* * *}$ \\
\hline \multicolumn{5}{|l|}{ Education } \\
\hline ISCED 0-2 & $0.080^{* * *}$ & $0.073^{* * *}$ & $0.069^{* *}$ & $0.057^{*}$ \\
\hline ISCED 3-4 & 0.006 & 0.011 & -0.002 & -0.005 \\
\hline \multicolumn{5}{|l|}{ ISCED 5-6 (reference category) } \\
\hline \multicolumn{5}{|l|}{ Age group } \\
\hline $50-59$ & $-0.126^{* * *}$ & $-0.085^{* * *}$ & $-0.128^{* * *}$ & $-0.037^{*}$ \\
\hline $60-69$ & $-0.053^{* *}$ & -0.024 & $0.053^{* *}$ & -0.012 \\
\hline \multicolumn{5}{|l|}{ 70-79 (reference category) } \\
\hline Leisure time very important & & $-0.029^{+}$ & & $-0.033^{*}$ \\
\hline Religious services not often & & $-0.148^{* * *}$ & & $-0.147^{* * *}$ \\
\hline Control over life - more control & & $0.030^{*}$ & & $0.029^{*}$ \\
\hline Women need children - no & & $-0.098^{* * *}$ & & $-0.092^{* * *}$ \\
\hline Marriage outdated institution - yes & & $-0.081^{* * *}$ & & $-0.038^{*}$ \\
\hline Women really want home - no & & -0.005 & & -0.017 \\
\hline Duty to respect parents - no & & -0.001 & & 0.001 \\
\hline Abortion approved & & $-0.073^{* * *}$ & & $-0.075^{* * *}$ \\
\hline ISEI & & & 0.000 & $-0.001^{*}$ \\
\hline \multicolumn{5}{|l|}{ Marital status } \\
\hline Married currently or formerly & & & & $2.257^{* * *}$ \\
\hline \multicolumn{5}{|l|}{ Never married (reference category) } \\
\hline Country - 37 contrasts not shown & yes & yes & yes & yes \\
\hline AIC & 21964 & 21861 & 21965 & 20834 \\
\hline BIC & 22250 & 22203 & 22259 & 21189 \\
\hline
\end{tabular}

Note: ${ }^{+} p<0.1,{ }^{*} p<0.05,{ }^{* *} p<0.01,{ }^{* * *} p<0.001$.

Source: EVS 2008.

\subsection{Poisson regression analysis}

The association between education and fertility is strongly negative for women, but is not consistently negative for men in the age groups with almost completed fertility. In this section, I investigate the extent to which these differences can be explained by variations in socioeconomic status and value systems across the different levels of education.

As the distribution of the dependent variable "number of children" best fits the Poisson distribution, I use a Poisson regression adjusted for underdispersion of the dependent variable. For both samples, I estimate the simple education-fertility association. I then add values connected to the SDT to the second model and 
Figure 3:

Mean number of children: differences in coefficients by education and welfare regime (male sample)

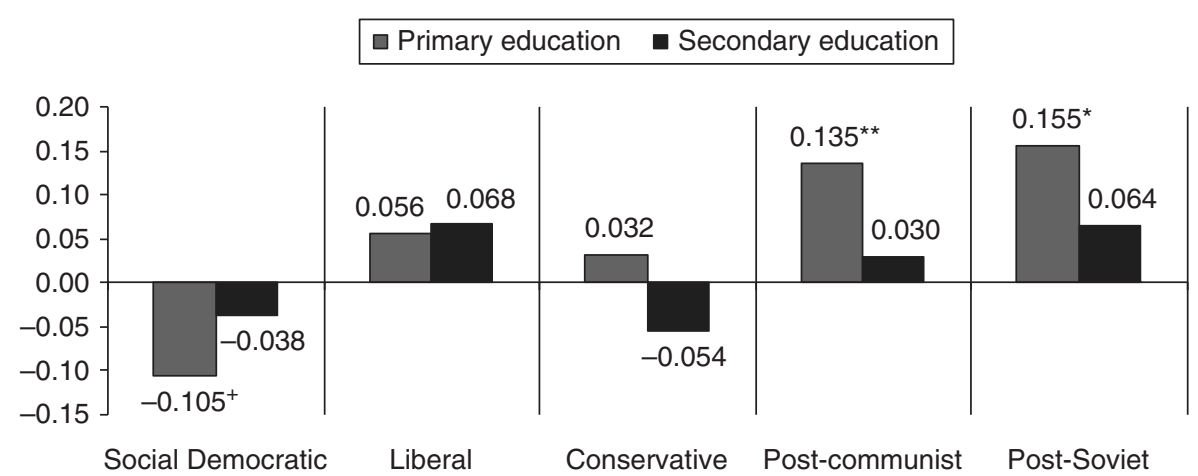

Notes: Tertiary education is a reference category; the figure is based on the results of Model 4, including all control variables. ${ }^{+} p<0.1,{ }^{*} p<0.05,{ }^{* *} p<0.01,{ }^{* * *} p<0.001$.

Source: EVS 2008.

socioeconomic status to the third model to test whether these variables improve the model, and to see how they change the effect of education. The final model containing all of the control and explanatory variables is estimated for each welfare regime group to investigate whether there are differences in the education-fertility link under various welfare conditions. ${ }^{7}$

Table 2 shows the results of the Poisson regression for the sample of men. In Model 1, there is a significant difference between men with tertiary and with primary education, but not between men with tertiary education and with secondary education. The exponentiation of the coefficient 0.08 means that the men with primary education have a mean number of children that is 1.083 times higher. The effect of the age group is as expected: i.e. men in the younger age groups have lower fertility levels.

The values associated with the SDT enter the analysis in Model 2. The lower AIC and BIC values indicate an improvement of the model, and the coefficient for primary education is slightly lower. In Model 3, socioeconomic status, as measured by ISEI, is not shown to be significant or to improve the first model. Surprisingly, the coefficient for primary education is lower in Model 3 than in the previous models.

The last model in Table 2 (Model 4) includes all of the control and explanatory variables. The coefficient for primary education has a p-value of 0.018 , and the value

\footnotetext{
7 An interaction between education and age group was tested as a part of this final model to reflect various educational compositions and the consequences of attained education for particular age groups. However, as this interaction was not significant and did not improve the model for either gender, it is not presented in the final version of the analysis.
} 
Table 3:

Unstandardized coefficients of the Poisson regression for the "number of children" variable (female sample)

\begin{tabular}{|c|c|c|c|c|}
\hline & Model 5 & Model 6 & Model 7 & Model 8 \\
\hline Intercept & $0.596^{* * *}$ & $0.885^{* * *}$ & $0.683^{* * *}$ & $2.183^{* * *}$ \\
\hline \multicolumn{5}{|l|}{ Education } \\
\hline ISCED 0-2 & $0.260^{* * *}$ & $0.233^{* * *}$ & $0.147^{* * *}$ & $0.104^{* * *}$ \\
\hline ISCED 3-4 & $0.090^{* * *}$ & $0.077^{* * *}$ & 0.025 & -0.003 \\
\hline \multicolumn{5}{|l|}{ ISCED 5-6 (reference category) } \\
\hline \multicolumn{5}{|l|}{ Age group } \\
\hline $40-49$ & $-0.063^{* * *}$ & -0.015 & $-0.066^{* * *}$ & 0.004 \\
\hline $50-59$ & $-0.039^{*}$ & -0.001 & $-0.041^{*}$ & -0.005 \\
\hline $60-69$ & -0.029 & -0.006 & -0.026 & -0.006 \\
\hline \multicolumn{5}{|l|}{ 70-79 (reference category) } \\
\hline Leisure time very important & & $-0.050^{* * *}$ & & $-0.041^{* * *}$ \\
\hline Religious services not often & & $-0.072^{* * *}$ & & $-0.074^{* * *}$ \\
\hline Control over life - more control & & 0.008 & & 0.011 \\
\hline Women need children - no & & $-0.166^{* * *}$ & & $-0.125^{* * *}$ \\
\hline Marriage outdated institution - yes & & $-0.051^{* * *}$ & & $-0.027^{+}$ \\
\hline Women really want home - no & & $-0.029^{*}$ & & -0.017 \\
\hline Duty to respect parents - no & & 0.017 & & 0.018 \\
\hline Abortion approved & & $-0.084^{* * *}$ & & $-0.078^{* * *}$ \\
\hline ISEI & & & $-0.004^{* * *}$ & $-0.003^{* * *}$ \\
\hline \multicolumn{5}{|l|}{ Marital status } \\
\hline Married currently or formerly & & & & $1.193^{* * *}$ \\
\hline \multicolumn{5}{|l|}{ Never married (reference category) } \\
\hline Country - 37 contrasts not shown & yes & yes & yes & yes \\
\hline AIC & 38493 & 38286 & 38417 & 37148 \\
\hline BIC & 38811 & 38664 & 38743 & 37541 \\
\hline
\end{tabular}

Note: ${ }^{+} p<0.1,{ }^{*} p<0.05,{ }^{* *} p<0.01,{ }^{* * *} p<0.001$.

Source: EVS 2008.

of the coefficient itself is 0.057 ; this means that men with primary education have a mean number of children that is 1.059 times higher. In Model 4, five out of eight of the values connected with the SDT are statistically significant, and explain the relationship in the expected way. More liberal attitudes and behaviors are found to be associated with both higher education and lower fertility, including attitudes regarding attendance at religious services, women's need for children, and abortion; as well as, albeit to a lesser extent, views on the importance of leisure time and on whether marriage is an outdated institution. The more liberal values and the higher ISEI scores of highly educated men explain a portion of the negative association 


\section{Figure 4:}

Mean number of children: differences in coefficients by education and welfare regime (female sample)

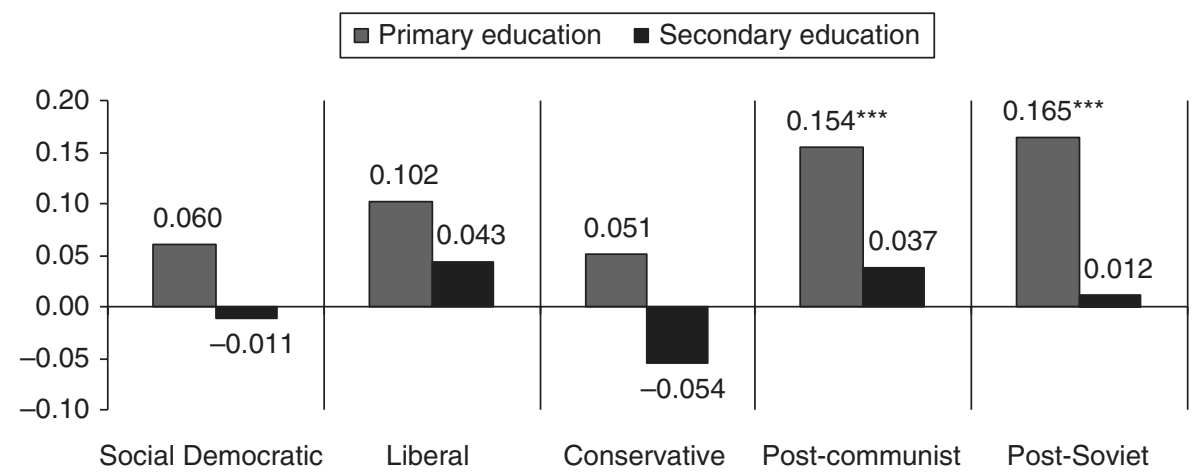

Notes: Tertiary education is a reference category; the figure is based on the result of Model 8, including all control variables. ${ }^{+} p<0.1,{ }^{*} p<0.05,{ }^{* *} p<0.01,{ }^{* * *} p<0.001$.

Source: EVS 2008.

between education and number of children. However, only a small part of the effect of education is explained by the explanatory variables.

Figure 3 elaborates on the role of the macro context by presenting the coefficients of education from Model 4 for each type of welfare regime. The coefficient of primary education is negative only in countries with Post-Communist and PostSoviet welfare models, and is slightly positive in countries with Social Democratic welfare regimes; which makes for an interesting western-eastern division.

Estimations of the same models for the sample of women are presented in Table 3. The association between education and fertility is much stronger among women, and both coefficients of education are highly significant (Model 5). Primary education increases the mean number of children by 29.7 percent, while secondary education increases the mean number of children by 9.4 percent. As expected, these effects are much larger than they are among men.

Model 6 shows that adding items of the SDT value index to the model for the sample of women reduces the education-fertility link, although the association remains very strong. Much lower coefficients of education are shown in Model 7, in which the ISEI scale is added to the estimation process: under these conditions, women with secondary education do not differ from women with tertiary education. The differences between women with primary education and with tertiary education are also much smaller than before. Hence, a lower level of education is associated with higher fertility, mainly because of lower socioeconomic status, and secondarily because of more traditional values. However, there is still a large unexplained difference between the categories of primary and tertiary education. 
All of the explanatory and control variables together are controlled for in Model 8. While the coefficients for education are lower in this model, the statistical significance remains the same. Women with primary education have a mean number of children that is 1.11 times higher than that of women with tertiary education, while the category of secondary education does not differ from the reference category. The coefficients for age group are not significant. In the model, marital status is less important, and socioeconomic status is much more important for women than for men.

The number of children is predicted by the same values connected with the SDT as it is in the sample of men; some coefficients differ in their absolute value, but the substantive findings are identical. More liberal attitudes and behaviors concerning leisure time, religious services, women's need for children, and abortion are associated with both a higher level of education and lower fertility; and all of these attitudes mediate the relationship between fertility and education to some degree. Generally, women with primary education still have a higher number of children than more educated women, but the size of the coefficient is reduced, especially after controls for socioeconomic status and values are applied.

The differences across welfare regimes are tested in the same way as for the sample of men. Figure 4 shows that the effect of primary education is significant only in countries with the two types of post-communist models: namely, the PostCommunist and the Post-Soviet welfare regimes.

\section{Conclusion and discussion}

The main expectations hypothesized in this paper have been confirmed by the analysis. The education-fertility link was shown to be generally negative. The link was found to be much weaker for men (indeed, in the sample of men no differences were found between those with secondary education and those with tertiary education) than for women. Furthermore, a large share of the initial association between fertility and education found for women in the Poisson regression analysis could be explained by socioeconomic status and values associated with the SDT, while only a small share of the initial effect found for men in the same analysis could be explained by these factors. The only remaining effect of education found for men and women is a relatively small coefficient for primary education, if all of the selected variables are controlled for.

The education-fertility link for men was slightly reduced when values connected with the SDT and socioeconomic status entered the analysis, although the coefficient for socioeconomic status was not found to be significant or to improve the initial model. It appears that among more educated men, the high opportunity costs of having children, which might have led them to have fewer children; were largely offset by their greater financial resources, which made it easier for them to have more children. Among women, the same association was shown to decrease considerably when values and especially socioeconomic status entered the analysis. 
Compared to highly educated men, women with higher levels of education were significantly more constrained in their childbearing by their high socioeconomic status and more liberal values, which explains the more negative effect of education found among women.

For both men and women, the characteristics connected to education were found to explain most - but not all - of the education-fertility link. Additional analysis on how the effect of education differs by welfare model showed that for both sexes, the negative effect of primary education remained significant under the PostCommunist and Post-Soviet welfare regimes. In contrast, this effect was found to be non-significant in countries with Social Democratic, Liberal, and Conservative welfare regimes. This finding may be partly explained by the low availability of effective contraception in many countries under communist regimes (Dudová 2009; Gjonca et al. 2008).

In addition, the results show that the indicators of both the theory of value change and the rational choice theory could be used to explain the educationfertility link. First, it may be assumed that women with high levels of education and high socioeconomic status have fewer children than their less educated counterparts primarily because of their higher opportunity costs and greater workfamily conflicts (Neels and De Wachter 2010; Sobotka 2004). Second, it may be assumed that for both men and women, educational differences in fertility can be partly explained by differences in value systems: i.e. compared to less educated people, highly educated people tend to put greater emphasis on liberal and postmodern values, which may be less compatible with childbearing (Bachrach 2001; Inglehart 1971, 1990). Among the values shown to be closely correlated with childbearing behavior were attitudes toward abortion, women's need for children, and leisure time; as well as attendance at religious services. In sum, the effect of educational attainment on fertility was not shown to be decisive; instead, almost all of the educational differences in fertility could be explained by controlling for the other properties associated with education. It therefore appears that the observed education-fertility link is not universal, and can be mostly explained by other individual characteristics closely related to education.

While the EVS dataset has certain advantages, it also has some weaknesses. First, European populations are culturally and socially heterogeneous. It is therefore possible that some of the survey questions were understood differently in different contexts due to translation inconsistencies or differences in the cultural meaning of a question. Second, as the data are cross-sectional, it is not appropriate to interpret the relationships as causal. The relationships among the variables are thus only associations at a given time point. The education-fertility link is often interpreted as the effect of education on fertility, even in cross-sectional studies (Dreze and Murthi 2001; James et al. 2012); but the same results can also be interpreted as representing the effect of fertility behavior on education. For example, people who have more children may have completed a lower level of education because of early childbearing (De Vaus 2002; Stange 2011). It should also be noted that the respondents' characteristics were measured a long time after their childbearing had 
been completed, and that their values may have changed over time (Bardi et al. 2009, 2014; Lesthaeghe and Moors 2002; Rokeach 1985). Hence, the findings of this study should be further tested on panel data. Third, the results presented in this paper are for cohorts born in 1967 and earlier. The findings would likely be different for younger generations of potential or actual parents. Despite these drawbacks, using the EVS dataset to address the education-fertility link is a valuable contribution to knowledge in this area.

\section{Acknowledgements}

This work was supported by the Grant Agency of Masaryk University under the project MUNI/A/1317/2016.

\section{References}

Aldieri, L. and C. P. Vinci 2013. Education and fertility: A comparative micro-econometric analysis in Europe. The European Journal of Comparative Economics 10(1): 109-120.

Andersson, G., M. Rønsen, L. B. Knudsen, T. Lappegård, G. Neyer, K. Skrede, K. Teschner and A. Vikat 2009. Cohort fertility patterns in the Nordic countries. Demographic Research 20: 313-351.

Bachrach, Ch. 2001. Comment: The puzzling persistence of postmodern fertility preferences. A supplement to Population and Development Review 27: 332-338.

Bardi, A. and R. Goodwin 2011. The dual route to value change: Individual processes and cultural moderators. Journal of Cross-Cultural Psychology 42(2): 271-287.

Bardi, A., J. A. Lee, N. Hofmann-Towfigh and G. Soutar 2009. The structure of intraindividual value change. The Journal of Personality and Social Psychology 97: 913-929.

Bardi, A., K. E. Buchanan, R. Goodwin, L. Slabu and M. Robinson 2014. Value stability and change during self-chosen life transitions: Self-selection vs. socialization effects. Journal of Personality and Social Psychology 106(1): 131-147.

Barthold, J. A., M. Myrskylä and O. R. Jones 2012. Childlessness drives the sex difference in the association between income and reproductive success of modern Europeans. Evolution and Human Behavior 33(6): 628-638.

Becker, G. S. and H. G. Lewis 1974. Interaction between Quantity and Quality of children. In Economics of the family: Marriage, children, and human capital, ed. T. W. Schultz, 81-90. Chicago: University of Chicago Press.

Brand, J. E and D. Davis 2011. The impact of college education on fertility: Evidence for heterogeneous effects. Demography 48(3): 863-887.

Bongaarts, J. 2010. The causes of educational differences in fertility in Sub-Saharan Africa. Vienna Yearbook of Population Research 8: 31-50.

Center for Disease Control and Prevention 2012. National Vital Statistics Reports [electronics resource]. Hiatsville: National Center for Health Statistics.

http://www.cdc.gov/nchs/data/nvsr/nvsr61/nvsr61_01.pdf. 
Cleland, J. 2002. Education and future fertility trends, with special reference to midtransitional countries. In Completing the fertility transition, 187-202. United Nations.

Dallal, G. E. 2008. The little handbook of statistical practice. Washington: Amazon Digital Services LLC.

De Vaus, D. 2002. Fertility decline in Australia. Family Matters 63: 14-21.

Dreze, J. and M. Murthi 2001. Fertility, education, and development: Evidence from India. Population and Development Review 27(1): 33-63.

Dribe, M. and M. Stanfors 2009. Education, work and parenthood: Comparing the experience of young men and women in Sweden. Journal of Family and Economic Issues 30(1): $32-42$.

Dudová, R. 2009. Interrupce v socialistickém Československu z foucaultovské perspektivy. Gender, rovné př́ležitosti, výzkum 10(1): 25-36.

Ebbinghaus, B. 2012. Comparing welfare state regimes: Are typologies an ideal or realistic strategy? Edinburgh: European Social Policy Analysis Network, ESPAnet Conference.

Esping-Andersen, G. 1990. The three worlds of welfare capitalism. Princeton: Princeton University Press.

European Values Study 2010. EVS 2008 Method Report No. 2010/17, Bonn: GESIS.

Fenger, H. J. M. 2007. Welfare regimes in Central and Eastern Europe?: Incorporating post-communist countries in a welfare regime typology. Contemporary Issues and Ideas in Social Sciences 3(2): 1-30.

Gauthier, A. H. 2007. The impact of family policies on fertility in industrialized countries: A review of the literature. Population Research and Policy Review 26(3): 323-346.

Gjonca, A., A. Aassve and L. Mencarini 2008. Albania?: Trends and patterns, proximate determinants and policies of fertility change. Demographic Research 19(11): 261-293.

Goren, P. 2005. Party identification and core political values. American Journal of Political Science 49(4): 881-896.

Hoem, J. M. 2003. Autonomy or conservative adjustment? The effect of public policies and educational attainment on third births in Austria, 1975-96. Vienna Yearbook of Population Research 1: 101-119.

Human Fertility Database 2015. Age-Specific Birth Counts [electronics resource]. Max Planck Institute for Demographic Research (Germany) and Vienna Institute of Demography (Austria). http://www.humanfertility.org.

Inglehart, R. 1971. The silent revolution in Europe: Intergenerational change in post-industrial societies. The American Political Science Review 65(4): 991-1017.

Inglehart, R. 1981. Post-materialism in an environment of insecurity. The American Political Science Review 75(4): 880-900.

Inglehart, R. 1985. Aggregate stability and individual level flux in mass belief systems: The level of analysis paradox. The American Political Science Review 79(1): 97-116.

Inglehart, R. 1990. Culture shifts in advanced industrial society. Princeton: Princeton University Press.

Inglehart, R. F. 2008. Changing values among western publics from 1970 to 2006. West European Politics 31(1-2): 130-146.

James, K. S., V. Skirbekk and J. Van Bavel 2012. Education and the global fertility transitionforeword. Vienna Yearbook of Population Research 10: 1-8. 
Kalwij, A. 2010. The impact of family policy expenditure on fertility in Western Europe. Demography 47(2): 503-519.

Kravdal, O. 2007. Effect of current education on second- and third-birth rates among Norwegian women and men born in 1964: Substantive interpretations and methodological issues. Demographic Research 17: 211-245.

Kravdal, O. and R. R. Rindfuss 2008. Changing relationships between education and fertility: A study of women and men born 1940 to 1964. American Sociological Review 73(5): 854-873.

Lanzieri, G. 2013. Fertility statistics in relation to economy, parity, education and migration. Eurostat. Retrieved 18/2/2015 from http://ec.europa.eu/eurostat/statistics-explained/index. php/Fertility_statistics_in_relation_to_economy,_parity,_education_and_migration.

Lappegård, T. and M. Rønsen 2013. Socioeconomic differences in multipartner fertility among Norwegian men. Demography 50(3): 1135-1153.

Lesthaeghe, R. 2010. The unfolding story of the second demographic transition. Population and Development Review 36(2): 211-251.

Lesthaeghe, R. 2011. The "second demographic transition": A conceptual map for the understanding of late modern demographic developments in fertility and family formation. Historical Social Research 36(2): 179-218.

Lesthaeghe, R. and G. Moors 2002. Life course transitions and value orientations: Selection and adaptation. In Meaning and choice: Value orientations and life course decisions, ed. R. Lesthaeghe, 2-40. The Hague and Brussels: NIDI-CBGS publications No. 37.

Lutz, W. 2010. Education will be at the heart of 21st century demography. Vienna Yearbook of Population Research 8: 9-16.

Marchini, J. 2008. Lecture 5: The Poisson Distribution, Oxford. Retrieved 6/9/2016 from http://www.stats.ox.ac.uk/ marchini/teaching/L5/L5.notes.pdf.

Mareš, P. 2008. Hodnota dítěte v životě českých rodin. In Rodina, děti a zaměstnánív České společnosti, eds T. Sirovátka and O. Hora, 97-118. Boskovice: Albert.

McDonald, P. 2002. Sustaining fertility through public policy: The range of options. Population (English Edition) 57(3): 417-446.

Mikołajczak, M. and J. Pietrzak 2014. Ambivalent sexism and religion: Connected through values. Sex Roles 70: 387-399.

Musick, K., P. England, S. Edgington and N. Kangas 2009. Educational differences in intended and unintended fertility. Social Forces 88(2): 543-572.

Neels, K. and D. De Wachter 2010. Postponement and recuperation of Belgian fertility: How are they related to rising female educational attainment? Vienna Yearbook of Population Research 8: 77-106.

Nisén, J., P. Martikainen, K. Silventoinen and M. Myrskylä 2014. Age-specific fertility by educational level in the Finnish male cohort born 1940-1950. Demographic Research 31(5): 119-136.

Rokeach, M. 1979. Understanding human values. New York: The Free Press.

Rokeach, M. 1985. Inducing change and stability in belief systems and personality structures. Journal of Social Issues 41(1): 153-171.

Rokeach, M. and S. J. Ball-Rokeach 1989. Stability and change in American value priorities, 1968-1981. American Psychologist 44(5): 775-784. 
Schwartz, S. H. 2005. Robustness and fruitfulness of a theory of universals in individual values. In Valores e trabalho [Values and work], eds A. Tamayo and J. B. Porto, 1-46. Brasilia: Editora Universidade de Brasilia.

Sobotka, T. 2004. Postponement of childbearing and low fertility in Europe. Amsterdam: Dutch University Press.

Sobotka, T. 2008a. Overview Chapter 6: The diverse faces of the Second Demographic Transition in Europe. Demographic Research 19: 171-224.

Sobotka, T. 2008b. Does persistent low fertility threaten the future of European populations? In Demographic challenges for the 21st Century. A state of art in demography, eds J. Surkin, P. Deboosere and J. Van Bavel. Brussels: VUBPRESS.

Sobotka, T., V. Skirbekk and D. Philipov 2011. Economic recession and fertility in the developed world. Population and Development Review 37(2): 267-306.

Stange, K. 2011. A longitudinal analysis of the relationship between fertility timing and schooling. Demography 48(3): 931-956.

Surkyn, J. and R. Lesthaeghe 2004. Value orientations and the Second Demographic Transition (SDT) in Northern, Western and Southern Europe: An update. Demographic Research, Special collection 3: 45-86.

Testa, M. R. 2014. On the positive correlation between education and fertility intentions in Europe?: Individual- and country-level evidence. Advances in Life Course Research 21: 28-42.

Thévenon, O. and A. H. Gauthier, 2011. Family policies in developed countries: A 'fertilitybooster' with side-effects. Community, Work E Family 14(2): 157-216.

Toulemon, L., A. Pailhé and C. Rossier 2008. France?: High and stable fertility. Demographic Research 19(16): 503-556.

Van Bavel, J. and J. Rózańska-Putek 2010. Second birth rates across Europe: Interactions between women's level of education and child care enrolment. Vienna Yearbook of Population Research 8: 107-138.

van de Kaa, D. J. 2001. Postmodern fertility preferences: From changing values orientation to new behavior. A supplement to Population and Development Review 27: 290-331.

Zhang, L. 2011. Male fertility patterns and determinants. Dordrecht: Springer. 
